Mini Review

\title{
Mini review on important biological properties of benzofuran derivatives
}

\begin{abstract}
Benzofuran derivatives are an important heterocyclic compounds that are possess vital biological activities such as antidepressant, anticancer, antiviral, antifungal, antioxidant, anti-psychotic etc. Substituted benzofurans also posses other applications such as fluorescent sensor, antioxidants, oxidant, brightening agents and in other field of chemistry and agriculture. Benzofurans presents in various natural products with various physiological, pharmacological and toxic properties.
\end{abstract}

Keywords: Benzofuran derivatives; Heterocyclic compounds; Biological properties; Antidepressant; Anticancer; Antiviral; Antifungal; Antioxidant; Anti-psychotic
Volume 3 Issue 2 - 2016

Mohammad Asif

Department of Pharmacy, Uttarakhand Technical University, India

Correspondence: Mohammad Asif, Department of Pharmacy, Uttarakhand Technical University, GRD(PG)IMT, Dehradun, 248009, Uttarakhand, India, Email aasif32I@gmail.com

Received: September 21, 2016 | Published: September 28, 2016

\section{Introduction}

Benzofurans nucleus presents in various synthetic as well as natural compounds and have diverse biological activities and their potential applications as pharmacological agents. ${ }^{1}$ Several benzofuran containing various substituents at the $\mathrm{C}-2$ position are extensively presented in natural products. There are well known natural benzofuran compounds, which are isolated from Krameria ramosissima, Machilus glaucescens, Ophryosporus lorentzii, Ophryosporus charuaand Zanthoxylum ailanthoidol. The most acknowledged benzofurans are amiodarone, ailanthoidoland bufuralol. Ailanthoidol is a neolignan with a 2-arylbenzofuran skeleton, was isolated from the Zanthoxylum ailanthoides. The neolignans and lignans are having various types of biological activities like immune-suppressive, anticancer, antiviral, antioxidant, antifeedant and anti-fungal activities. Amiodaroneis a highly effective antiarrhythmic agent. ${ }^{2}$ The 2-substituted benzofurans have received a great interest for their anti-HIV, ${ }^{3}$ anticancer and antimicrobial ${ }^{4-7}$ activities. The derivatives of keto benzofuran are useful in medicines, like amiodarone and benziodarone, mainly for the treatment of pathological syndromes of the cardio-vascular disorders, like arrhythmia. ${ }^{8}$ Some benzofurans were possessing anticonvulsant and anti-inflammatory activities. Some amino-benzofurans are exhibited antiarrhythmic activity. ${ }^{9}$ The most renowned benzofurans are amiodarone, angelicin, xanthotoxin, bergapten, nodekenetin and usnic acid compounds ${ }^{1,10}$ (Figure 1).

\section{Chemistry of benzofuran}

The benzene ring is fused with five member furan ring and formed bicyclic ring benzofuran or coumarone.

\section{Synthesis of benzofuran}

Benzofuran was first prepared from coumarin with name coumarone. The intermediate 3,4-dibromo-3,4-dihydrocoumarin with $\mathrm{KOH}$ leading to benzofuran by PERKIN rearrangement (Figure $2 \&$ 3). ${ }^{11}$

\section{Important examples of drugs which contain benzofuran moiety}

It has been reported that Benzofuran derivatives possess a variety of biological activities such as anticancer, antiviral, immunosuppressive, antioxidant, anti-fungal and other useful activities.

Antifungal agents: Griseofulvin is an antifungal drug (Figure 4).

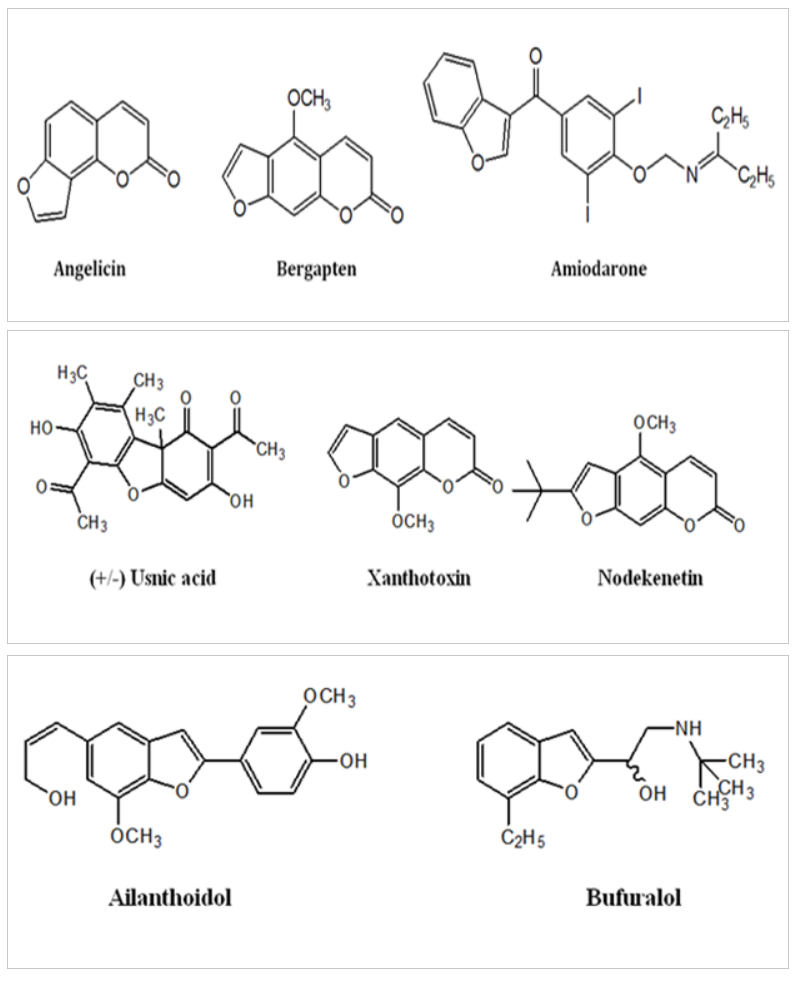

Figure I Benzofuran containing some drug molecules.

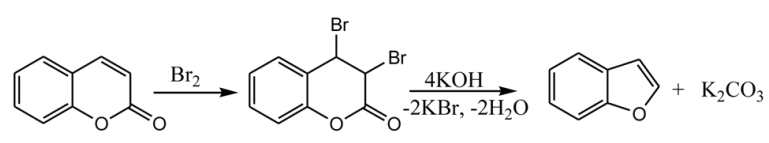

Figure 2 The thermal cyclodehydration of 2-alkylphenols leads to 2-alkylbenzofurans.

CNS stimulant agents: The 5-APDB (5-(2'-aminopropyl)-2, 3-dihydrobenzofuran) and 6-APDB (6-(2'-aminopropyl)-2,3dihydrobenzofuran) is a reputed entactogen drug of the phenethylamine and amphetamine classes (Figure $5 \& 6$ ).

Anti-arrhythmic agents: Amiodarone is an anti-arrhythmic agent used for both ventricular and supraventricular arrhythmias. 
Dronedarone is mainly used for the indication of cardiac arrhythmias (Figure $7 \& 8$ ).<smiles>[R]CCc1ccccc1C</smiles>

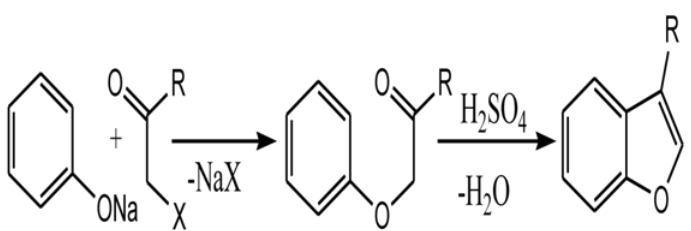

Figure 3 Benzofurans are available by reaction of phenolates with halo ketones pursued by cyclodehydration with $\mathrm{H}_{2} \mathrm{SO}_{4}$, polyphosphoric acid or zeolites.<smiles>COC1=CC(=O)C[C@H](C)C12Oc1c(Cl)c(OC)cc(OC)c1C2=O</smiles>

Figure 4 Griseofulvin.

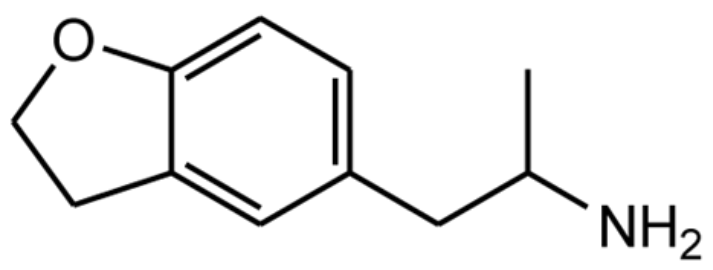

Figure 5 5-APDB.

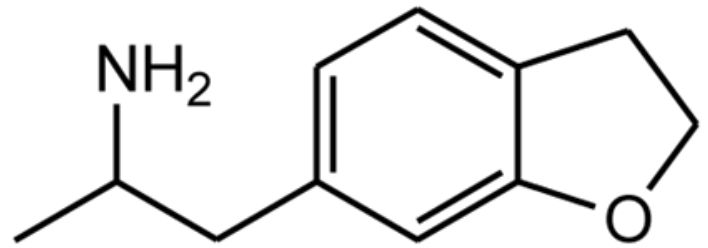

Figure 6 6-APDB.<smiles>CCC(CC)=NCOc1c(I)cc(C(=O)c2coc3ccccc23)cc1I</smiles>

Figure 7 Amiodarone.

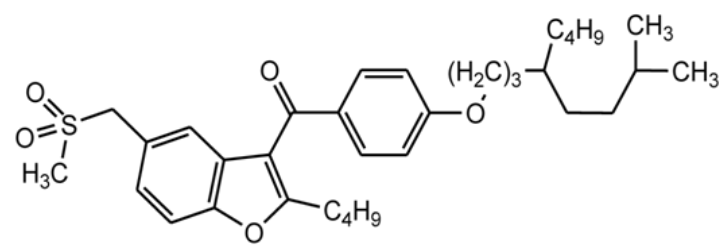

Figure 8 Dronedarone.

Antihypertensive agents: Benziodarone and Cloridarol are vasodilators (Figure $9 \& 10$ ).<smiles>CCc1oc2ccccc2c1C(=O)c1cc(I)c(O)c(I)c1</smiles>

Figure 9 Benziodarone.<smiles>OC(c1ccc(Cl)cc1)c1cc2ccccc2o1</smiles>

Figure 10 Cloridarol.

Serotonin receptors agonist: Dimemebfe is an agonist of the $5-\mathrm{HT}_{1} \mathrm{~A}$ and 5- $\mathrm{HT}_{2}$ serotonin receptors (Figure 11).<smiles>COc1ccc2occ(Cl)c2c1</smiles>

Figure II Dimemebfe.

$\boldsymbol{\alpha}_{2}$-adrenergic antagonist: Efaroxan is a $\alpha_{2}$-adrenergic antagonist (Figure 12).<smiles>CCC1(C2=NCCN2)Cc2ccccc2O1</smiles>

Figure 12 Efaroxan.

Antipsychotic agents: Elopiprazole is a phenylpiperazine class drug and have antipsychotic activity (Figure 13).

Anti-gout agent: Benzbromarone is a uricosuric agent used for the treatment of gout, mainly when first-line treatment (by use of allopurino) fails or produces intolerable adverse effects (Figure 14). 


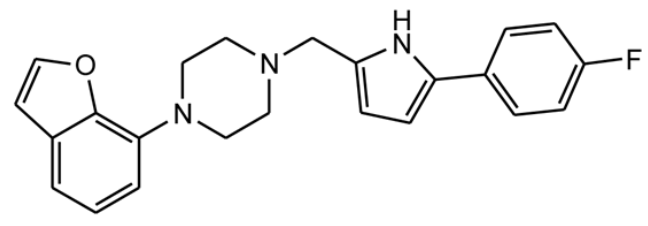

Figure 13 Elopiprazole.

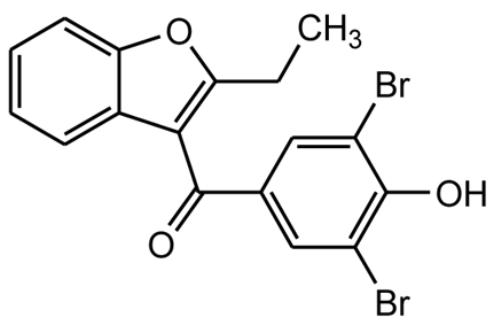

Figure I 4 Benzbromarone.

Antidepressant agent: Vilazodone is an antidepressant and used for the treatment of mental depressive disorders (Figure 15).<smiles>CN1CCN(c2ccc3oc(C(N)=O)cc3c2)CC1</smiles>

Figure 15 Vilazodone.

Muscles relaxant agent: TC-5619 is acts as a partial agonist at the $\alpha 7$ subtype of the neural nicotinic acetylcholine receptors (Figure 16).<smiles>O=C(CC1C2CCC(C2)N1Cc1cccnc1)c1cc2ccccc2o1</smiles>

Figure 16 TC-5619.

\section{Conclusion}

The importance of benzofurans justifies the constant efforts directed toward the improvement of new, selective, and competent production of these heterocyclic compounds.

\section{Acknowledgments}

None.

\section{Conflicts of interest}

The authors declare no conflict of interest.

\section{Funding}

None.

\section{References}

1. Kirilmis C, Ahmedzade M, Servi S, et al. Synthesis and antimicrobial activity of some novel derivatives of benzofuran: Part 2. The synthesis and antimicrobial activity of some novel 1-(1-benzofuran-2-yl)-2mesitylethanone derivatives. European Journal of Medicinal Chemistry. 2008;43(2):300-308.

2. Koca M, Sevi S, Kirilmis C, et al. Synthesis and antimicrobial activity of some novel derivatives of benzofuran:Part 1. Synthesis and antimicrobial activity of Benzofuran-2-yl-(3-phenyl-3-methylcyclobutyl)-ketoxime derivatives. Eur J Med Chem. 2005;40(12):1351-1358.

3. Rida SM, Hawash ESAM, Fahmyl HTY, et al. Synthesis and In Vitro Evaluation of Some Novel Benzofuran Derivatives as Potential Anti-HIV-1, Anticancer, and Antimicrobial Agents. Arch Pharm Res. 2006;29(1):16-25

4. James LT, Carly AP, Erik CM, et al. Sequence selective recognition of DNA by hairpin conjugates of a racemic secocyclopropaneindoline-2benzofurancarboxamide and polyamides. Bioorganic \& Medicinal Chemistry Letters. 2002;12(16):2245-2248.

5. Urzua A, Echeverria J, Rezende MC, et al. Antibacterial Properties of $3 \mathrm{H}$-Spiro[1-benzofuran-2,1'-cyclohexane] Derivatives from Heliotropium filifolium. Molecules. 2008;13(10):2385-2393.

6. Khan W, Alam MJ, Rashid M, et al. A new structural alternative in benzo[b]furans for antimicrobial activity. Bioorganic \& Medicinal Chemistry. V;13(16):4796-4805.

7. Kawasaki K, Masubuchi M, Morikami K, et al. Design and synthesis of novel benzofurans as antifungal agents targeting fugal $\mathrm{N}$ myristoyltransferase Part 3. Bioorg Med Chem Lett. 2003;13(1):87-91.

8. Hu K, Jeong JH. A Convergent synthetic study of Biological active Benzofuran derivatives. Arch Pharm Res. 2006;29(6):476-478.

9. Dawood KM, Gawad AH, Rageb EM, et al. Synthesis, anticonvulsant, and anti-inflammatory evaluation of some new benzotriazole and benzofuran-based heterocycles. Bioorg Med Chem. 2006;14(11):36723680 .

10. Gabriele B, Mancuso R, Salerno G. ANovel Synthesis of 2-Functionalized Benzofurans by Palladium-Catalyzed Cycloisomerization of 2-(1Hydroxyprop-2-ynyl)phenols Followed by Acid-Catalyzed Allylic Isomerization or Allylic Nucleophilic Substitution. J Org Chem. 2008;73(18):7336-7341.

11. Eicher T, Hauptmann S, Speicher A. The Chemistry of Heterocycles Structure, Reactions, Syntheses and Applications. Wiley-vch Gmbh \& Co., Germany; 2003. p. 63-64. 